\title{
New data on cranial anatomy of the ceratopsian dinosaur Psittacosaurus major
}

Hai-Lu You, Kyo Tanoue, and Peter Dodson

Acta Palaeontologica Polonica 53 (2), 2008: 183-196 doi:http://dx.doi.org/10.4202/app.2008.0202

An exceptionally preserved skull and mandible of ceratopsian dinosaur Psittacosaurus major revealed many anatomical details such as the existence of an elliptical median interpremaxillary foramen, a prominent neurovascular canal on the internal wall of the beak, long, slightly divergent basipterygoid processes developed as vertical blades with a deep cleft between them, and horizontally oriented vomer. The new specimen shows two autapomorphies of An exceptionally preserved skull and mandible of ceratopsian dinosaur Psittacosaurus major revealed many anatomical details such as the existence of an elliptical median interpremaxillary foramen, a prominent neurovascular canal on the internal wall of the beak, long, slightly divergent basipterygoid processes developed as vertical blades with a deep cleft between them, and horizontally oriented vomer. The new specimen shows two autapomorphies of Psittacosaurus major, the transversely narrow dorsal skull roof and very prominent dentary flanges, confirming the presence of two large-skulled psittacosaur species in the Lujiatun Bed of the Lower Cretaceous Yixian Formation in Beipiao City, western Liaoning Province, China, the long- and narrow-skulled $P$. major, and broad-skulled $P$. lujiatunensis.

Key words: Dinosauria, Ceratopsia, Psittacosaurus, Cretaceous, Yixian Formation, Liaoning, China

Hai-Lu You [youhailu@gmail.com], Institute of Geology, Chinese Academy of Geological Sciences, 26 Baiwanzhuang Road, Beijing 100037, P.R. China; Kyo Tanoue [tanoue@sas.upenn.edu], Department of Earth and Environmental Science, University of Pennsylvania, 240 S. 33rd Street, Philadelphia, PA 19104-6316, USA; Peter Dodson [dodsonp@vet.upenn.edu], School of Veterinary Medicine and Department of Earth and Environmental Science, University of Pennsylvania, 3800 Spruce Street, Philadelphia, PA 19104-6045, USA.

This is an open-access article distributed under the terms of the Creative Commons Attribution License (for details please see creativecommons.org), which permits unrestricted use, 
distribution, and reproduction in any medium, provided the original author and source are credited.

Faf Full text $(618.3 \mathrm{kB})$ 